
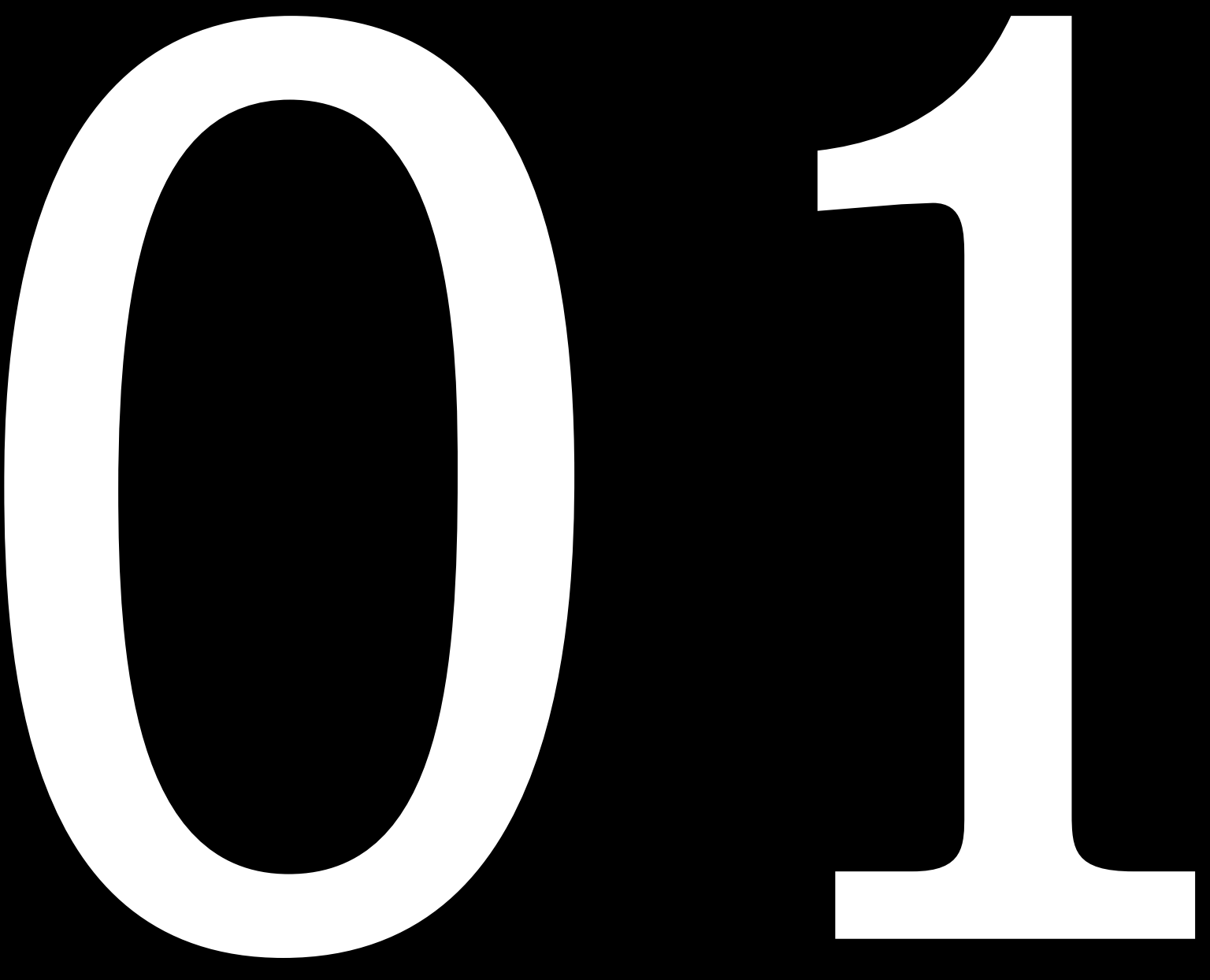

DOI: https://doi.org/10.14483/2422278X.13799 


\section{Características de la élite colombiana a partir de los líderes de la izquierda: de la Violencia al posconflicto $^{1}$}

Characterising the Colombian elite from leftist leaders: From La Violencia to postconflict period

Características da elite colombiana baseadas nos líderes da esquerda: da Violência ao pós-conflito

\section{Hugo Altamirano Acevedo ${ }^{2}$ (i)}

Para citar este artículo: Altamirano, H. (2019). Características de la élite colombiana a partir de los líderes de la izquierda: de la Violencia al posconflicto. Ciudad Paz-ando, 12(2), 9-19. doi: https://doi.org/10.14483/2422278X.13799

Fecha de recepción: 29 de agosto de 2018

Fecha de aprobación: 27 de marzo de 2019

1 Artículo de investigación, derivado de la tesis de la maestría en Análisis de Problemas Políticos, Económicos e Internacionales Contemporáneos (Universidad Externado de Colombia), titulada: Perspectiva de los líderes de la izquierda colombiana, respecto de la incidencia de la elite en el origen la Violencia (1946-1953), finalizada en 2017.

2 Magíster en Análisis de Problemas Políticos, Económicos e Internacionales Contemporáneos; Licenciado en Ciencias Sociales; estudiante de la Especialización en Educación y Gestión Ambiental, Universidad Distrital Francisco José de Caldas. Correo electrónico: haltamiranoa@correo. udistrital.edu.co, ORCID https://orcid.org/0000-0001-8622-9743 


\section{RESUMEN}

La Violencia en Colombia es un periodo de tiempo en el cual se exacerba la criminalidad durante el siglo XX, en específico entre las décadas del 40 y 50. El presente artículo es una indagación desde los líderes de la izquierda colombiana, de finales del siglo XX y principios del siglo XXI, sobre las características de la élite del país, a partir de la Violencia de los40hasta el proceso de paz con las Fuerzas Armadas Revolucionarias de Colombia (Farc-Ep) y los acercamientos con la guerrilla denominada Ejército de Liberación Nacional (ELN). La metodología implicó una serie de entrevistas seguidas del respectivo rastreo bibliográfico, dando como resultado similitudes con otras élites y diferencias en cuanto a la redistribución de la riqueza, movilidad social y circulación de las élites. Palabras clave: Colombia, democracia, élite, ideología, paz, violencia.

\section{ABSTRACT}

In Colombia, La Violencia was a period of aggravated crime that occurred during the 20th century, particularly between the 1940s and 1950s. This article analyses the Colombian leftist leaders from the end of the 20th century to the beginning of the 21 st century by studying the characteristics of the country's elite; furthermore, it also analyses the phase beginning from La Violencia in the 1940s to the peace process with the Revolutionary Armed Forces of Colombia and the reconciliation with the National Liberation Army guerrilla. The methodology of the study involved a series of interviews followed by their respective bibliographic tracking, which results in similarities with other elites and differences in wealth redistribution, social mobility and circulation of elites.

Keywords: Colombia, democracy, elite, ideology, peace, violence.
A Violência na Colômbia é um período de tempo em que a criminalidade é exacerbada durante o século XX, especificamente entre 1940 e 1950. Este artigo é um inquérito dos líderes da esquerda colombiana no final do século XX e início do século XXI sobre as características da elite do país, desde a Violência dos 40 até o processo de paz com as Forças Armadas Revolucionárias da Colômbia (FARC-Ep) e a aproximação com a guerrilha chamada Exército de Libertação Nacional (ELN). A metodologia envolveu uma série de entrevistas seguidas do respectivo rastreamento bibliográfico, resultando em semelhanças com outras elites e diferenças em termos de redistribuição de riqueza, mobilidade social e circulação de elite.

Palavras-chave: Colômbia, democracia, elite, ideologia, paz, violência. 


\section{Introducción}

El siguiente artículo hace parte de una investigación sobre el origen de la Violencia en Colombia en el periodo 1946-1953, se basa en una serie de entrevistas a líderes de la izquierda del país realizadas entre 2015 y 2016, en medio del proceso de paz con el grupo guerrillero Farc-Ep que culminó a finales del 2016 y de los acercamientos con el ELN llevados a cabo por el expresidente Juan Manuel Santos. En este contexto, el objetivo se cifró en conocer el punto de vista de estos líderes sobre la élite, desde la Violencia hasta la actualidad, presumiendo la relación élite-Violencia.

En este artículo se acogen ideas que sobre la élite colombiana han emergido en los entrevistados y, por tanto, en la izquierda del país. Sus puntos de vista han hecho parte del debate político y electoral en diferentes instancias durante décadas, siendo también referentes y participantes directos en acercamientos hacia procesos de paz como es el caso del recientemente fallecido Carlos Lozano Guillén, figura política de amplia trayectoria en la izquierda colombiana, quien al final de su vida se desempeñó como escritor y director del semanario de izquierda Voz Proletaria. Las entrevistas se extendieron, además, a la presidenta de la Unión Patriótica y representante a la cámara para el periodo 2018-2022 Aída Avella; Omer Calderón, expresidente de la Unión Patriótica y catedrático de la Universidad Distrital; Jaime Caycedo, secretario general del Partido Comunista Colombiano y catedrático universitario; Iván Cepeda, exrepresentante y senador por el Polo Democrático Alternativo para los períodos 2014-2018 y 2018-2022, y Hollman Morris, precandidato a la alcaldía de Bogotá D.C. y concejal de la misma ciudad por el Movimiento Progresista para el periodo 2016-2019.

En las entrevistas, realizadas durante un año, los participantes desplegaron sus puntos de vista en torno a diferentes aspectos y en lo que toca a este artículo, es decir, las características de la élite. El texto se subdividió en tres categorías: la primera se orientó hacia la idea de quiénes eran los representantes de la élite en Colombia, la segunda versa sobre la evolución de este sector de la sociedad y, finalmente, las características de la élite que para los entrevistados tenían mayor significado.

Metodológicamente se partió de un rastreo bibliográfico en torno al problema de las élites y la Violencia en Colombia, lo que condujo a una revisión de la historia de las mentalidades como método para la elaboración de un cuestionario de entrevista destinado a los líderes de la izquierda colombiana. Para su escogencia se optó por un criterio reputacional, es decir, se tomó en cuenta su reconocimiento dentro de los partidos o movimientos políticos, influencia en la toma de decisiones y participación en procesos electorales (Duque, 2005).

El método historia de las mentalidades fue referente en cuanto se trataba de encontrar al ser humano en el espacio del miedo, la violencia, las clases sociales, la visión acerca de la élite y la izquierda como intermediario cultural de ideas y corrientes de pensamiento, las cuales circulan en su propio escenario, transportándose luego a espacios como la política, la academia y los medios de comunicación (Vovelle, 1991). En este caso, el discurso de la izquierda es una forma de resistencia que, al decir de Vovelle, surge de lo marginal; este puede ser posicionado dentro de lo anormal por la élite, que es quien identifica a aquellos que rechazan el orden establecido y define lo normal, lo sospechoso y lo que debe ser marginado, reprimido y excluido. Lo anterior en el contexto del conflicto armado que, como todos, establecen una ruptura fundamental de los valores y que, según Bouthoul: "transforman las reglas [...] de la moral y del derecho $[\ldots]$ y se instauran [...] los ritos de destrucción" (Bouthoul, 1971).

\section{La Violencia en Colombia}

La Violencia en Colombia es un período de tiempo que genera discusión entre los teóricos, pues para estos el año de inicio más antiguo es 1945 (Sánchez, 2009) y el más reciente 1966 (Oquist, 1978). No obstante, otras interpretaciones como la de los libros La Violencia en Colombia y Los años del olvido datan 1930 como un antecedente más que relevante (Guzmán, Fals y Umaña, 1980; Guerrero, 1991).

Desde el punto de vista teórico, Montenegro y Posada (2001) expresan que el fenómeno se puede ver desde las visiones tradicionales, donde la violencia es una constante en la historia del país, y desde los nuevos estudios que se basan en las cifras de muertes violentas (Deas y Gaitán, 1995). Dentro de estas teorías, especialmente en lo que respecta a los nuevos estudios, existen interpretaciones sobre las causas de la violencia entre las que se encuentran: el marxismo, que argumenta la violencia como respuesta a una sociedad profundamente injusta y restringida, y la exclusión, que encuentra en métodos violentos la búsqueda de realización frente a un Estado que responde con represión y persecución (Montenegro y Posada, 2001).

\section{El concepto de élite}

En principio, es posible decir que el término corresponde al verbo francés elire que significa escoger, es decir, la élite correspondería a un grupo de personas escogidas de la sociedad. A principios del siglo XX el término indicaba a quienes, por sus aptitudes, destacaban frente al promedio general (Ruiz, 2009); posteriormente, Gaetano Mosca planteó que en todas las sociedades existen dos clases, gobernantes y gobernados, donde la primera ejerce la función política y de poder y goza de las ventajas que le proporciona este monopolio, mientras que en la segunda, más numerosa que la primera, recae su poderío (2006). A esta clase gobernante es la que Mosca denominó "clase 
política” (2006, p. 106), definición con sentido más político y equiparable al término élite.

Según Laura Baca Olamendi (2001), la evolución de la palabra continuó con Vilfredo Pareto, quien propuso la diferencia entre una élite gobernante que ejerce directamente el poder y otra no gobernante, conformada por los mejores individuos, pero no participante en el poder. Más adelante, Robert Michels cuestionó planteamientos como la idea de democracia y circulación de las élites, mientras que Joseph Chumpeter, con el acumulado teórico, propone integrar las teorías (Baca, 2001). El debate continuó con la edición del libro La élite del poder de Charles Wright Mills en 1956, donde el autor analizó el problema de la élite en los Estados Unidos, lo cual le permitió definirla como:

una serie de grupos cuyos individuos se conocen entre sí, se relacionan [...] en la vida social y en la vida de los negocios, y así, al tomar decisiones se toman en cuenta unos a otros [...] la élite se considera a sí misma, y es considerada por los demás, como el círculo íntimo de las altas clases sociales. (Wright, 2005, p. 18)

Consecutivamente, otros analistas destacaron en el razonamiento, entre ellos Paul Sweezy y Robert Dahl. Últimamente Giovanny Sartori ha hecho acotación al aporte de Lasswell en una de cuyas definiciones dice que "las élites son aquellas con el máximo poder en un grupo" (2005, p. 185); la definición conduce a pensar que se pasa del mérito de Pareto al demérito. Hilando más sobre la frase, agregó el autor que, tratándose del "poder controlador de los grupos controladores", se tiene que decir que no todos los grupos controladores son "minorías de élite" en el sentido de Pareto, sino minorías de poder en el sentido de Lasswell (Sartori, 2005), definición que se ajusta mejor al punto de vista de los entrevistados.

\section{Representantes de la élite en Colombia}

La conformación de la élite colombiana, según Álvaro Echeverri Uruburu (1997), muestra que en la composición de los gremios no existe apoliticidad. En este sector, entre 1946 hasta la actualidad, hay coincidencia en los dirigentes del sector económico y el político en lo que últimamente se ha denominado "puerta giratoria", expresión usada para ejemplificar la manera como los dirigentes circulaban del sector político al económico y viceversa. Cabe anotar que, durante la mayor parte del siglo XX, los dirigentes empresariales, gremiales y políticos ostentaban varios cargos a la vez.

En su libro Élites y proceso politico en Colombia 19501978, Echeverri (1997) sostiene que la causa de que las clases dominantes sean las proveedoras de la élite económica y política se puede hallar en el intervencionismo estatal formalizado en 1936, año a partir del cual surgieron las más importantes organizaciones gremiales. Esta situación forzó el planteamiento de un tipo de relaciones con el Estado tendientes a permitirles mayor influencia y unificación de intereses (Echeverri, 1997).

Las organizaciones gremiales en su dirigencia tomaron líneas liberales, conservadoras o compartidas, sus dirigentes hacían parte de grupos familiares históricamente reconocidos. Así, en las organizaciones gremiales de la década del 40 se pueden observar en forma recurrente apellidos como Ospina Pérez, Lleras Restrepo, Espinosa, Echavarría, Lloreda, Ramírez Ocampo, Galán, Gómez, Pastrana Borrero, Barco Vargas y López, familias que han hecho parte de la política y economía desde aquellos años hasta la actualidad (Echeverri, 1997). Estos son los más representativos del panorama analizado por Echeverri y, en uno u otro grado, coinciden con lo expresado por los dirigentes entrevistados.

En esta medida, la representante de la Unión Patriótica Aída Avella, sostiene que de la élite hacen parte personas que han estado en la presidencia y quienes actualmente aspiran al poder: "no es sino mirar a los presidentes [...] y mirar a quienes están aspirando en este momento" (Entrevista Avella, 2016). Este modo de ver concuerda con lo expresado por el expresidente de la Unión Patriótica Omer Calderón, quien opina que las candidaturas presidenciales son un indicador de las familias en el poder, unas hacen parte de la política y otras de la posesión de la tierra:

mire usted no más las candidaturas presidenciales que hemos tenido todos estos años y verá que hacen parte de las mismas familias que se han ubicado como representantes de las élites de poder [...]. Son élites políticas que representan intereses de las élites económicas o de las élites de los hacendados o de los terratenientes [...]la familia Lleras, la familia Pastrana [...], los Santos. (Entrevista Calderón, 2015)

Por su parte, el secretario general del Partido Comunista de Colombia Jaime Caycedo sostiene que se trata de una oligarquía que se ha mantenido en el poder por generaciones, familias en las cuales el control del poder se conserva mediante vínculos matrimoniales cercanos:

la asemejan bastante al viejo concepto de castas y por lo tanto mantienen a lo largo de generaciones una especie de aristocracia del poder y de control de los instrumentos de poder [...]. Hay mucha endogamia [...] dentro de esas élites colombianas para el manejo del poder y para la transmisión de las influencias, y hoy en día, de las palancas de la corrupción, del enriquecimiento y de la acumulación de capital. (Entrevista Caycedo, 2015)

Álvaro Echeverri considera que tales alianzas matrimoniales permiten observar unificación de intereses 
económicos en una tendencia endogámica, característica de la élite del país que los sociólogos denominan "sistema de élite entrelazada" (1997, p. 87).

Concordando con la idea de élite como familias que han ejercido el gobierno, Iván Cepeda incluye a la familia Gómez, además de las ya citadas, pero según él han surgido nuevos rivales en líderes regionales como el caso de los expresidentes Gaviria y Uribe Vélez (Entrevista Cepeda, 2015). Por su parte, Carlos Lozano señaló que cuando se habla de élites en Colombia se trata de grupos económicos que igualmente son familias entre las que se encuentran "el grupo Santo Domingo, el grupo de Ardila Lulle, [...] sindicato antioqueño, las grandes empresas del país [...]. Otras empresas y una fuerte inversión extranjera" (Entrevista Lozano, 2016). Sumándose a Caycedo, dice Lozano, en una expresión muy cercana a la ya citada de Wright Mills, que tal élite se compone de un grupo muy reducido y estable que se entrelaza y toma las decisiones:

hay un entramado que es muy limitado, muy reducido, antes se hablaba de cien familias o yo no sé cuántas [...], pero sí es un círculo [...] muy pequeño que cierra la brecha y la mantiene así: [...] son ellos los que definen, [...] son ellos los que manejan todo, son ellos los que controlan todo y son ellos los que pelean y se unen en función de sus intereses. (Entrevista Lozano, 2016)

Buscando contextualizar un poco más, se debe decir que esta alusión a las cien familias probablemente se refiere al debate que se presentó en el siglo pasado entre el historiador venezolano Vallenilla Lanz y expresidente Eduardo Santos, donde el primero sostuvo: "yo pregunto: ¿quién es el pueblo de Colombia? ¿Serán las cien familias que desde la independencia vienen figurando en el gobierno, constituyendo las dos oligarquías que se han disputado el poder, llamándose liberales y conservadores?" (Molina, 1982, p. 50).

La expresión de Vallenilla no cita referentes, sin embargo, sí se puede tratar de un número reducido, aunque difícil de establecer. Julio Silva, por ejemplo, hace una clasificación por monopolios y grupos financieros en Colombia en el que, si se descartan los extranjeros, se llegan a contar 41 familias (1990). Echeverri (1997) afirma que el número podría ser más amplio, tan solo en el lapso 1958-1962, en que el autor hace la ubicación de las élites en el aparato del Estado, hay más de 100 apellidos (p. 319), sin tener en cuenta las relaciones matrimoniales y de parentesco. Pero hay que tener en cuenta que Silva se basa en el factor económico, mientras que Echeverri Uruburu se extiende a lo político y militar. A modo de ejemplo, es pertinente citar a Fernando Álvarez (1995), quien en un artículo extiende el parámetro a las esferas de la salud, educación, transporte, medios de comunicación y la rama judicial.
Estos grupos, para Lozano Guillén, son reducidos, pero con un poder considerable, lo que les permite seguir en el poder bajo las condiciones que ellos estiman convenientes: "Son pequeños grupos pero con un gran poder, con un gran poder económico [...], gran poder político, que lo saben aprovechar [...] para mantener el ejercicio de poder, para poder controlarlo y mantener ese statu quo así" (Entrevista Lozano, 2016).

En el mismo sentido, Gaetano Mosca plantea la existencia de la clase política como una minoría que hace uso de las ventajas que le proporciona el monopolio del poder, y que cuenta con unas cualidades materiales, intelectuales y morales (reales o aparentes) que la hacen diferente de los gobernados y que también le otorgan autoridad sobre ellos. Sin embargo, es la mayoría quien le ha entregado la dirección, o más bien, esta minoría ha logrado imponerse sobre la mayoría gracias a esa condición minoritaria que le facilita estar organizada y obedecer a un único impulso (2006, p. 110).

\section{Evolución de la élite colombiana}

El propósito siguiente es analizarlos cambios que ha tenido la élite colombiana desde los años 40 hasta la actualidad, en medio del contexto histórico de la Violencia, a partir de las opiniones de los dirigentes de izquierda. Como una forma de contextualización, Carlos Lozano expone que en el origen de la Violencia se presenta una confrontación entre partidos que con el tiempo encuentran cierto grado de solución, convirtiéndolos en socios, y donde incluso las diferencias de tipo ideológico se zanjan para repartirse el poder, práctica que ha permanecido en el tiempo. En este sentido:

el periodo de la Violencia en Colombia, que marcó toda esa época de la mitad del siglo hasta el Frente Nacional, que incluye la parte de la dictadura militar, generó una confrontación entre partidos tradicionales muy grande [...]. El Bogotazo, que llaman, terminó con un Gobierno de coalición en el cual los liberales entraron a gobernar. Después de que estaban era reclamando el poder y la destitución de Ospina Pérez, terminaron apoyándolo y cogobernando [...]. Cuando la dictadura militar de Rojas Pinilla no se convirtió en una marioneta de esos partidos, ni funcional a ellos, decidieron acabarla y formar el Frente Nacional; eso hizo acabar esas diferencias ideológicas. Aunque históricamente los dos partidos se habían enfrentado en el escenario político, siempre que se amenazó el interés de clase de estos se unieron [...]. El Frente Nacional, un pacto político bipartidista, le pone punto final a esa confrontación fuerte, casi que antagónica, y los convierte en socios, socios del poder, y hace borrar esas barreras ideológicas e incluso socioeconómicas [...]. Yo creo que hoy ellos son socios todavía, a pesar de las contradicciones que tienen, y ahí se ven, en todos los gobiernos ahí están y se reparten la torta del poder. (Entrevista Lozano, 2016) 
El proceso analizado por Lozano efectivamente describe la ruta donde, en medio del levantamiento popular del 9 de abril de 1948 llamado el Bogotazo, las principales cabezas del liberalismo pidieron la dimisión del presidente conservador Mariano Ospina Pérez, para luego ceder y dar paso a un gobierno de unión nacional. Esta unión se expresó en la aceptación que hizo el dirigente liberal Darío Echandía del Ministerio de Gobierno y el respaldo de la dirección liberal confirmado por radio días después (Tirado, 1989; Abella, 1973). Tras el acuerdo, la fase violenta continuó y se agudizó, por lo que los dos partidos condujeron un proceso que culminó en un golpe de Estado en 1953. Asimismo, estos partidos promovieron la conclusión de la dictadura en 1957, que dejó el poder en manos de una Junta Militar de Gobierno y dio paso a la conformaron el Frente Nacional, un pacto con el que los partidos tradicionales se repartieron el poder por dieciséis años entre 1958 y 1974. De este modo, se encontraron intereses comunes entre los dos partidos que los condujeron a la alianza.

Para Aída Avella la élite colombiana se transforma creando unos mecanismos que les permiten constantes ventajas, un ejemplo de ellos son los avales electorales otorgados por los partidos o representantes de los partidos, condicionando a quienes los reciben y permitiendo que solo algunos escogidos hagan parte de quienes controlan el partido político y el acceso al poder: "esos amarres electorales de los avales de los unos, de los otros [...] se inventaron los umbrales, se inventaron las cifras repartidoras pa' quedarse con todo" (Entrevista Avella, 2016). Además, según la representante de la Unión Patriótica, las élites se han transformado y transforman la sociedad con el objetivo de obtener ganancias, multiplicarlas y permitir un sistema de corrupción a través de los contratos. Afirma que:

Cuando en todos los países del mundo la carga, las grandes mercancías se llevan en tren, aquí los pocos que teníamos los destruyeron [...], entonces ahora son grandes buses, tractomulas que destruyen las carreteras, carreteras que hay que estarlas [...] saneando cada rato, con tratos que hay que hacer [...]. Pero lo que más aterra en este momento es que los contratos para llevar los alimentos a los colegios se hagan para justificar una serie de robos, muchos van a incidir en las decisiones electorales porque quienes se quedan con el dinero de esas comidas van a nutrir a los políticos que llegan al parlamento, entonces es un parlamento que llega con muchos votos. (Entrevista Avella, 2016)

Los contratos, además, no se basan en necesidades ni en eficiencia, sino en conveniencias de los contratistas: "tienen que entregar el café con leche de Teusaquillo a Ciudad Bolívar para las escuelas" (Entrevista Avella, 2016). El trayecto, que significa más de una hora, puede determinar la justificación de mayores ventajas económicas de los contratistas. Además, en los contratos se manifiestan otros beneficios como la comodidad y restricción del acceso de proponentes sobre las necesidades de los beneficiarios. Avella señala que "hay una inmensa responsabilidad de esta élite en conservar una serie de privilegios con base en el hambre y la necesidad de la gente" (Entrevista Avella, 2016).

La líder política de la Unión Patriótica considera igualmente que la élite ha puesto el Estado a su servicio y ha experimentado lo que ella llama "mutaciones", es decir, que la élite se transforma y transforma a las instituciones en la búsqueda de mayores beneficios, incluso creando cargos innecesarios:

algunas personas de la élite eran grandes industriales y esa gran industria se acabó, y la acaban porque [...] era mucha carga [...] que a un trabajador le pagaran sus cesantías, le pagaran para su pensión de jubilación [...].El Estado da puestos, entonces los puestos son del político, no es de la gente, no es de la necesidad de un país [...]. Claro, nos dicen que aquí hay concursos hasta para los notarios, puede haber concursos, pero hay escogencia. (Entrevista Avella, 2016)

En un sentido similar, Omer Calderón dice que la élite tiene presencia o influencia directa en el Estado, la normatividad y las estructuras del poder, razón por la cual no importa si el gobernante proviene o no de la élite. Se puede decir que, para Calderón, la élite ha creado una estructura que le permite controlar al Estado y a los gobiernos a través de las normas, las cuales también son acompañadas por otros poderes:

tenemos unos sectores dominantes, unas élites que tienen presencia o influencia directa en el Estado, pero más que eso en la normatividad o en las estructuras de poder que el Estado representa. Puede que los gobernantes tengan un origen popular, incluso Belisario Betancur no provenía directamente de las grandes élites. Otro ejemplo, en la alcaldía de Bogotá tuvimos a Lucho Garzón que tampoco proviene de ninguna de las élites, pero las estructuras, las prácticas, las políticas, el poder militar, el poder económico, es el que está determinando el sentido de las políticas que rigen en el país. (Entrevista Calderón, 2015)

Para Omer Calderón la élite colombiana no ha evolucionado, ha configurado el poder como un fortín del que obtiene favores y privilegios, actuando en la misma lógica de los españoles en el período colonial, no desarrollando, sino extrayendo. Los logros sociales han sido producto de acciones populares en torno a una élite caracterizada por la búsqueda de conservación de privilegios y evasión de impuestos. Según el dirigente se trata de: 
unas élites [...] cuyo principal propósito en el caso del país ha sido la de asumir al Estado colombiano como un fortín del cual obtiene créditos y usos. Es la misma lógica, incluso, con la que llegaron los españoles a estas tierras [...], no con la idea de organizar la sociedad, no con la idea de hacer un determinado orden económico que permitiese el desarrollo económico o el despliegue de la producción nacional, no con el propósito de satisfacer necesidades de la población y, de paso, obtener utilidades, sino con el propósito de saquear el Estado o de saquear la sociedad [...].El Estado está condenado de tal manera que privilegia fundamentalmente las condiciones de reproducción del capital o de las ganancias de las grandes élites [...]. Buena parte de las cosas que uno podría buscarle de positivas a las élites dominantes han sido resultado de las luchas de los sectores sociales alternativos y de los sectores sociales no dominantes en el país. Mientras a nivel de las élites han tratado siempre de conservar la mayor cantidad de privilegios para tratar de evadir impuestos. (Entrevista Calderón, 2015)

De la misma manera que Calderón, el concejal Hollman Morris piensa que la evolución ha sido limitada y que lo conseguido es reflejo de grandes esfuerzos. Para él, un ejemplo de lo logrado es la Constitución de 1991, una Carta Política que con el tiempo se ha ido reformando: "ha sido muy poca la evolución y lo que se ha logrado de conquistas democráticas, ha sido muy duro, ha tenido unos costos muy grandes [...]. La Constitución del 91 [...] que posteriormente hemos venido viendo cómo se desmonta paulatinamente" (Entrevista Morris, 2016).

Para Iván Cepeda, la evolución en la élite colombiana es un proceso iniciado en la posesión de la tierra y que se dirigió hacia asociaciones con otros sectores de la producción, en el que el financiero ha cobrado cada vez más importancia: "un sector terrateniente tradicional [...] poco a poco ha ido asociándose con la agroindustria y también [...] con el extractivismo minero, e igual ha venido surgiendo un sector cada vez más importante que es el sector financiero" (Entrevista Cepeda, 2015).

Pero hay una evolución positiva en la actualidad, al menos en parte de la élite, que se verifica, según Caycedo, en el proceso de paz con las Farc:

la evolución positiva es el hecho de que hoy pueda hablarse, de que hay un sector mucho más convencido o persuadido de que se necesita una solución política de la guerra, para llegar a una forma de paz, de entendimiento, de reconciliación en el país y no mantener la vieja postura y de azuzar la guerra y de poner a los campesinos y a los hijos de los campesinos a matarse entre ellos. Creo que en ese sentido podría hablarse de que hay algo positivo, en medio de esta circunstancia. (Entrevista Caycedo, 2015)
En términos generales, según los dirigentes de la izquierda, la élite ha evolucionado creando y utilizando mecanismos legales y no legales como sistemas electorales, contratos, influencias y concursos que les permiten conservar el poder y servirse de él para conseguir beneficios; así también, han cambiado sus inversiones económicas sin que necesariamente hayan abandonado las tradicionales. Sin embargo, los partidos, movimientos de izquierda y otros sectores sociales y políticos han logrado cambios a través de mecanismos de presión.

Entre 1946 y 1953, los años más críticos del período de la Violencia en Colombia, la élite colombiana estaba dividida en los partidos Liberal y Conservador. Durante este lapso de tiempo, el Gobierno estuvo en manos del partido conservador y, aunque existía un distanciamiento con el partido Liberal, en los momentos más graves los dos partidos llegaron a acuerdos en los que las fuerzas de izquierda fueron excluidas. En ese sentido, no es contradictorio que estas élites hayan tenido que conducir procesos de paz con organizaciones armadas de izquierda en el curso de la historia.

Por otro lado, las élites del país se han servido del poder económico y político, donde el segundo está bajo la influencia del primero, incluso en procesos meritocráticos (en referencia a lo expuesto por Aída Avella), que están expuestos a la compra de exámenes, alteración de las exigencias en los concursos, falsificación de requisitos académicos o montaje de farsas sobre lo estudiado. Estas formas de corrupción aun hoy en día son muy difíciles de revelar y el sistema parece tener el propósito y diseño para no sancionarlas, quedando como única alternativa la censura pública. Al respecto, Gaetano Mosca infiere:

es inevitable que, cuando está prohibida la lucha a mano armada, y sólo se permite la que se hace a fuerza de los billetes, los puestos mejores sean conquistados por los que están más proveídos de billetes [...]. Estados Unidos [...], por ejemplo, [...] no impide que las elecciones se hagan a fuerza de dólares [...] y numerosas fracciones del congreso sean sensibles a la influencia de numerosas compañías [...]. También en la China [...] los grados académicos abrían el acceso a los cargos públicos y estos grados se obtenían mediante examen [...]. No sólo se compraba a menudo la indulgencia de los examinadores [...], sino que el gobierno mismo vendía por dinero los diversos grados académicos. (2006)

Finalmente, en cuanto a la búsqueda de unidad de la élite en los momentos de crisis, Gaetano Mosca afirma que está asociada a que el jefe de Estado requiere el apoyo de la clase dirigente para su buen ejercicio y sostenimiento. A su favor tiene que la clase dirigente no puede ponerse en su contra, pues esto podría determinar el surgimiento de otra clase que no tendría menor poder o influencia que la primera. Y si, en algún caso, la masa 
eliminara a la clase politica, de sí misma surgiría una nueva minoría organizada, es decir, otra clase política, la cual ocuparía el espacio de la anterior y cumpliría sus mismas funciones (Mosca, 2006).

\section{Características generales de la élite colombiana}

En términos generales, los dirigentes de la izquierda coinciden en que la élite colombiana se caracteriza por un ejercicio del poder por métodos violentos, fuerte interés sobre el poder económico y de acumulación de capital y un temor a perder o democratizar el poder que han mantenido durante un largo periodo, iniciado posiblemente en el origen de la República. Pero además de lo anterior, complementan y agregan otras características de manera particular.

La élite colombiana, piensa Aída Avella, retiene el poder en sus familiares como una forma de conservar la tierra, además de otras fuentes y dispositivos como los medios de comunicación que les permiten mantener sus mismas condiciones y ejercer un señorío sobre el pueblo:

Yo creo que no dejan el poder y la prueba está en que hay una serie de delfines por todas partes, de los que han tenido el poder. Sus familias no lo quieren dejar porque ha representado, también, no solamente la forma de mantener tierra [...]. Porque emisoras, por supuesto, reciben la orientación, entrevistan o no entrevistan gentes de acuerdo con el criterio del dueño del medio y el criterio de quienes dan la pauta publicitaria. (Entrevista Avella, 2016)

En este sentido, para Omer Calderón la razón de no democratizar el poder descansa en que la élite tiene muy poca legitimidad, "el principal temor de ellos es el de repartir el poder porque saben que su legitimidad es muy endeble" (Entrevista Calderón, 2015). La opinión permite asumir que esta élite piensa que el poder puede perderse si se amplía y que recuperarlo, dadas sus condiciones, es más difícil que retenerlo. Pero para Jaime Caycedo no necesariamente son temores, sino que una élite caracterizada por su hegemonía, cerramiento y capacidad de impedir la redistribución de la riqueza, existen intereses en explotar al Estado valiéndose de la corrupción:

no solamente son temores, son intereses y son intereses de acumular capital, de acumular poder, inclusive de poder usufructuar el Estado dolosamente a través de la corrupción y de los negociados [...], aquí lo que hay es unas élites cerradas que no admiten que realmente se puedan producir cambios que redistribuyan la riqueza. (Entrevista Caycedo, 2015)

La existencia de una élite ligada a la tierra y otra a la industria y al sector financiero, lleva a que no se haya hecho un uso debido del poder, se han impedido cambios fundamentales. Es esto lo que caracteriza a la élite colombiana, según Iván Cepeda, quien además considera que esta ha defendido el capitalismo y el neoliberalismo, sin tener en cuenta sus consecuencias, y no han permitido una reforma educativa con cobertura y calidad:

la élite [...] ha determinado el curso de la nación por su poder económico, político, militar y [...] no ha permitido que se den en Colombia los cambios básicos de lo que podría ser un modelo democrático y con una mínima justicia social, [...] han abogado por el capitalismo por el neoliberalismo, pero a diferencia de otras en el mundo [...] no han hecho una serie de reformas que permitan que ese modelo se desarrolle de una manera menos agresiva, con menos costos sociales, con menos derramamiento de sangre, en el caso de un país con los índices de violencia como tiene Colombia [...] ha impedido una reforma agraria [...], una reforma democrática, de división de poderes, de participación de sectores de oposición [...]. Ha impulsado toda clase de métodos violentos, entre esos la creación del paramilitarismo, el destinar las fuerzas militares a acciones que violan los derechos humanos, el entrar en pactos con el narcotráfico [...]. Ha negado una reforma educativa que permita el acceso [...] a todos los sectores a una educación con cobertura y calidad [...], la posibilidad de una reforma de ciertos aspectos de la economía urbana que den participación a sectores que han sido excluidos, que no ha permitido que las ciudades se desarrollen de manera armónica. (Entrevista Cepeda, 2015)

Coincidiendo en algunos aspectos con Iván Cepeda, Carlos Lozano agrega que se trata de una élite atrasada, con intereses en lo político y el poder, que se intranquiliza por un posible cambio del sistema económico:

La inquietud fundamental de la oligarquía colombiana no ha sido si va a haber paz o no, sino si va a haber cambio de sistema, [...] cambio del modelo neoliberal, [...] cambio de la llamada confianza inversionista, si se le va a seguir limitando aún más la presencia a las transnacionales aquí en Colombia, es decir, todo lo que tiene que ver con su interés económico que es por supuesto un interés político también, del ejercicio del poder. (Entrevista Lozano, 2016)

Desde su análisis, Lozano, al igual que Cepeda, plantea la posible existencia de dos tipos de élites en Colombia, pero para él no se tratan de élites repartidas según los sectores económicos, sino una que acompaña la paz y otra que no la acompaña o desconfía del proceso:

esas élites son muy atrasadas, demasiado atrasadas. Encontrar unos sectores realistas como en los sectores del poder que hoy han acompañado este proceso de paz, no es fácil, es difícil, mire el caso de este proceso de 
La Habana que se ha venido sacando adelante, pero en medio de un cerco y de un acoso de las élites que no lo acompañan o por lo menos lo ven con recelo. (Entrevista Lozano, 2016)

Como resumen de lo expuesto se puede decir que la élite colombiana se caracteriza por su cerramiento, atraso, poder familiar heredado, posesión de la tierra, manejo de los medios de comunicación, usufructo del Estado por medios corruptos, legitimidad endeble, inestabilidad en el apoyo a los procesos de paz, defensa del capitalismo, neoliberalismo, entorpecimiento a la redistribución de la riqueza y temor a un cambio de este modelo y todo lo que tiene que ver con su interés económico, político y del ejercicio del poder.

En lo que respecta a la violencia, capital y democratización o carácter cerrado de las élites colombianas, en párrafos anteriores ya se citó a Gaetano Mosca en torno a su carácter minoritario, monopolio del poder y uso de sus ventajas, pero además, el autor precisa que la clase política dirige y regula a los gobernados "de una manera más o menos legal, o bien de un modo más o menos arbitrario y violento" (2006, p. 106). Posteriormente agrega que "todas las clases políticas tienen la tendencia a volverse hereditarias, si no de derecho, al menos de hecho" (2006, p. 120). En lo que se puede observar que la democracia para algunas élites es un obstáculo a sus propósitos, pues les puede impedir la conservación del poder y sus privilegios. Entonces, la tarea de conservar el poder requiere que los allegados y familiares hagan parte de este; pero más adelante, Mosca precisa que "una clase política está tanto más expuesta a caer en estos errores cuanto más cerrada esté, si no legalmente, al menos de un modo efectivo, a los elementos provenientes de las clases inferiores" (2006), refiriéndose a que una élite cerrada puede confiarse de las clases inferiores al verlas en calma y correr el peligro de creer que será una situación permanente.

En este sentido, es pertinente aludir al concepto de circulación de las élites que José Darío Sáenz, citando a Pareto, la parafrasea como "la incesante renovación de los miembros de la élite en la sociedad en contra del carácter hereditario de esta, ya que los hijos no necesariamente adquieren las virtudes de sus padres" (2009). Lo anterior para indicar que, a pesar de la tendencia hereditaria, la élite debe aceptar el proceso de circulación en la que nuevos miembros entran en el sistema; sin embargo, en el caso colombiano parece ser que la entrada de nuevos miembros se presenta en forma muy lenta, sobre todo en lo que tiene que ver con los altos cargos.

Siguiendo el parámetro anterior, Sartori, aludiendo a Schumpeter, agrega que "la democracia es un subproducto de un método competitivo de reclutamiento de líderes" (2005), es decir, el proceso democrático no es la forma fundamental de cooptación de nuevos líderes. La democracia, en últimas, es una de las formas de que se sirve la élite en general, y la colombiana en particular, para sostenerse en el sistema, aunque no necesariamente para renovarse. Bouthoul expresa que este fenómeno de renovación de las élites no siempre se presenta, dando como ejemplo los casos de estancamiento de India y China. A partir de ello es posible reafirmar el concepto de "castas" utilizado por Caycedo, el cual es aludido en el mismo sentido por Bouthoul al decir que "el sistema de castas está basado, en última instancia, en una ideología familiar $\mathrm{y}$ en una doctrina que pone la herencia por encima de cualquier otra cualidad" (Bouthoul, 1971, p. 66).

En lo que hace referencia a la posesión de la tierra, corrupción, intereses y riqueza, Gaetano Mosca afirma que "las clases guerreras y dominantes acapararon la propiedad casi exclusiva de las tierras, que en los países no muy civilizados son la fuente principal de la producción de riqueza" (2006, p. 114). Vale la pena considerar que el autor hace referencia al Medioevo, no obstante, también es pertinente aclarar el carácter eminentemente rural de Colombia en la época de la Violencia, que persiste hoy a pesar del avance urbano. Al ser una fuente de riqueza, la tierra entra en el circuito de intereses y corrupción de la élite, dice el autor que:

así como el poder político produjo la riqueza, ahora la riqueza producirá el poder [...] estos individuos, que tienen en sus manos el manejo de centenares de millones, cuentan con medios variadísimos para presionar o atraer intereses muy extendidos, para intimidar o corromper a funcionarios. (Mosca, 2006)

Dentro de estos mecanismos para atraer y presionar se encuentran los medios de comunicación, afirma Mosca:

para que este último y eficacísimo medio de control pudiese iluminar realmente a la opinión pública, sería necesario que los diarios, y hoy también la radio no fuese el órgano de camarillas políticas o financieras, o instrumentos ciegos de una fracción. (2006, p. 325)

En relación con lo anterior, para el caso colombiano, unas veces más y otras menos, también, han significado medios de control y de manipulación, dependiendo de las circunstancias. En Colombia la aparición de cada nuevo medio de comunicación ha implicado su control por parte de la élite del país. Desde principios del siglo XX la línea política de los periódicos y de las empresas de radio era evidente y a partir de la llegada de la televisión los noticieros se fueron administrando por el partido Liberal y Conservador o controlados por las familias citadas, propensión descrita en el libro de Echeverri (1997, p. 62). En el caso de la izquierda colombiana, únicamente dos medios escritos han logrado reconocimiento nacional: el semanario Voz Proletaria y la desaparecida Revista Alternativa de los años 70. Los 
dos medios sufrieron de una u otra forma la censura del Estado (Bustos, 2015).

De este modo, la élite en Colombia constituye un círculo donde la política y la economía son los principales elementos de su interés, coadyuvados por los medios de comunicación, además de dispositivos de poder como la capacidad de mover funcionarios, nombrarlos, despedirlos, corromperlos e incluso intimidarlos. Lo anterior se constituye en una estructura que puede facilitarles la capacidad de elegir y hacerse elegir.

Por último, teniendo en cuenta lo referente a la educación, en determinados momentos esta ha sido limitada por la élite para evitar el avance de otras clases. Práctica complementada con una de mejor calidad para sus hijos que, sumada a las costumbres y lazos sociales e históricos, los llevan más allá de la instrucción, marcando diferencias que apartan y excluyen a los demás, transformándose en una forma de mantener el sistema. No obstante, este procedimiento puede traer consecuencias contrarias a lo esperado al tratarse de una forma de exclusión:

para una parte al menos de las clases inferiores, más que las privaciones, lo que puede amargarlas, es la existencia de un mundo superior del cual se ve excluida; un mundo cuyo acceso, sin estar prohibido por las leyes o por privilegios hereditarios, está obstaculizado por una trama de seda sutil, que muy difícilmente pueda superar: la diferencia de cultura, de maneras y de costumbres sociales. (Mosca, 2006, p. 166)

\section{Conclusiones}

En términos generales, élite del poder o clase política colombiana no difiere en mayor medida de las de otras épocas y lugares del mundo. Se constituye en un círculo de poder que tiende a perpetuarse y, para ello, utiliza los mismos mecanismos que la historia le ha proveído. Sin embargo, se pueden encontrar diferencias en aspectos como el uso excesivo de la violencia, la incapacidad de avanzar en la redistribución de la riqueza, promover la movilidad social a través de la educación y su baja circulación en el espacio de control, así como lo perciben los entrevistados.

Para los dirigentes de la izquierda colombiana, la élite se constituye en factor fundamental en la continuidad de la Violencia, al mantener prácticas y visiones de mundo que limitan las posibilidades de solución de los problemas sociales y parecen percibir que parte de la solución se encuentra en la apertura política.

En lo que tiene que ver con los excesos de la violencia, es evidente que en otros países del mundo se han dado fenómenos de apropiación de la tierra y desplazamiento por métodos violentos, es decir, la lucha por la tierra no explica la exacerbación de la violencia en Colombia, y expresarlo así es deshumanizar el conflicto. Incluso el despojo y el asesinato no necesariamente conducen a su despliegue. La diferencia en el caso del país se encuentra en que la violencia se extendió directamente a la familia y quebrantó la dignidad de las víctimas, lo que los condujo a una situación límite y a una respuesta proporcional. Esta respuesta se presenta ante una situación sin salida, dentro de unas acciones que vulneraron dignidades, valores sociales, costumbres y creencias. De esta manera, la violencia se dirigió en pos de una continua retaliación ante un vacío de justicia, la imposibilidad de acudir a los organismos y personas que encarnaban o simbolizaban los organismos de control y ante la ausencia de una seguridad más allá de la propia.

En lo que tiene que ver con la redistribución de la riqueza, aún en la actualidad, Colombia es uno de los países con mayor desigualdad. Pero el fenómeno no es reciente, en el libro Historia económica de Colombia (Ocampo, 1988) se menciona que los primeros estudios sobre la distribución del ingreso se hicieron en los 50 y mostraron al país como uno de los más desiguales del mundo, especialmente en el sector rural. Pero más aún, "la tendencia al deterioro en la distribución del ingreso se había iniciado a mediados de los años treinta [...] y se mantuvo al menos hasta mediados de la década del sesenta" (Ocampo, 1988, p. 328). El actual proyecto de reducción de tres dígitos en la moneda expone en su argumentación una alta economía a la que se le dificulta el manejo de las cifras y una baja que rechaza los billetes de las mayores denominaciones, revelando el desbalance.

El problema de la movilidad social ligado a la educación ha sido histórico, caracterizado por un limitado acceso a la educación superior de las clases populares, sumado al aumento en los costos de matrícula desde los 90. En la educación básica y media el proceso de deterioro se remonta a finales de 1960, contando actualmente con fórmulas de bachillerato y primaria semestralizadas, además de un largo período de promoción automática que continúa en muchos planteles, lo cual lleva al país a ocupar los últimos lugares en pruebas internacionales. Ocultar este despropósito ha conducido al cambio en las formas de evaluación y unificación de áreas por parte de los entes encargados de la educación.

Finalmente, en lo que tiene que ver con la baja circulación de las élites, especialmente en los altos cargos, hay que tener en cuenta que se trata de un proceso en el que los hijos de las familias históricas inician en las propias empresas o en el Gobierno con cargos de asesores, subsecretarios, vicecónsules y, muy rápidamente, son promovidos hasta llegar a los altos cargos, circuito en el que crean clientela, complicidades e intereses. De la misma forma, en el espacio democrático inician como contratantes, concejales o representantes directamente de la mano de sus familiares, y cuando la educación no es su virtud siempre queda la falsificación o farsas sobre títulos. 


\section{Referencias}

Abella, A. (1973). Asi fue el 9 de abril. Bogotá: Ediciones Aquí Bogotá.

Álvarez, F. (1995). Lazos familiares. Dinero. Recuperado de https://www.dinero.com/archivo/articulo/lazos-familiares/19245

Baca, L. (2001). Léxico de la politica. Ciudad de México: Fondo de Cultura Económica.

Bouthoul, G. (1971). Las mentalidades. Barcelona: Oikos-Tau.

Bustos, O. (Director). (2015). Hagamos memoria: historia de la Revista Alternativa [Película]. Colombia: Canal Capital.

Deas, M. y Gaitán, F. (1995). Dos ensayos especulativos sobre la violencia en Colombia. Bogotá: Tercer Mundo Editores.

Duque, J. (2005). La circulación de la clase política en Colombia: el Congreso de la República durante el Frente Nacional. Sociedad y Economía, 8, 29-60.

Echeverri, A. (1997). Élites y Proceso Politico en Colombia 1950-1978. Bogotá: Fundación Universidad Autónoma de Colombia.

Guerrero, J. (1991). Los años del olvido. Bogotá: Tercer Mundo Editores.

Guzmán, G., Fals, O. y Umaña, E. (1980). La Violencia en Colombia. Bogotá: Carlos Valencia Editores.

Molina, G. (1982). Las ideas liberales en Colombia. Bogotá: Tercer Mundo Editores.

Montenegro, A. y Posada, C. (2001). La violencia en Colombia. Bogotá: Alfaomega.
Mosca, G. (2006). La clase política. Ciudad de México: Fondo de Cultura Económica.

Ocampo, J. (Comp.). (1988). Historia económica de Colombia. Bogotá: Siglo XXI Editores.

Oquist, P. (1978). Violencia, conflicto y política en Colombia. Bogotá: Banco Popular.

Ruiz, J. (2009). Teoría política norteamericana sobre las elites. Su vigencia en el contexto político y económico actual. Espacios Públicos, 12(26), 169-189.

Sáenz, J. (2009). Configuración de una élite política en Cali: 1958-1998. Revista CS, 4, 147-175. https://doi. org/10.18046/recs.i4.439

Sánchez, G. (2009). Historiografía de la Violencia. En G. Sánchez y R. Peñaranda, Pasado y presente de la violencia en Colombia (pp. 17-32). Medellín: La Carreta Editores.

Sartori, G. (2005). Teoría de la Democracia. El debate contemporáneo. Madrid: Alianza Editorial.

Silva, J. (1990). Los verdaderos dueños del país. Bogotá: Fondo Editorial Suramérica.

Tirado, A. (Coord.). (1989). Nueva Historia de Colombia. Volumen II. Bogotá: Planeta Colombiana Editorial.

Vovelle, M. (1991). Aproximación a la historia de las Mentalidades colectivas. Cuadernos de Historia XII. Lima: Universidad de Lima.

Wright, C. (2005). La élite del poder. Ciudad de México: Fondo de Cultura Económica.

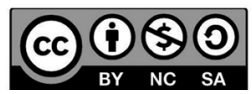

